\title{
Pattern of Fatal IntraAbdominal Injuries in Autopsy Cases- A 3 Year Retrospective Study
}

\author{
Khaja Azizuddin Junaidi ${ }^{1}$, Kashif $\mathrm{Ali}^{2}$ \\ ${ }^{I}$ Tutor, Department of Forensic Medicine, GIMS, Gulbarga, Karnataka, ${ }^{2}$ Senior Resident, Department of Forensic \\ Medicine, Jawaharlal Nehru Medical College, AMU, Aligarh, Uttar Pradesh
}

\begin{abstract}
Introduction- Abdominal trauma is an injury to abdomen and is a common presentation in the emergency room if it is caused by blunt force. According to WHO, in few years trauma will become the first or second leading cause of loss of productive years of life for both developed and developing countries. The most common cause of blunt abdominal trauma are road traffic accidents, fall from height, assaults, industrial accidents, etc.
\end{abstract}

Objective- To study the pattern and prevalence of abdominal injuries in relation to the various epidemiological factors.

Materials and Methods- This retrospective study was conducted over a period of 3 years from January 2016 to December 2018. The total number of cases studied were 120 showing abdominal injuries. This study on medicolegal autopsies was carried out at mortuary of Jawaharlal Nehru Medical College, Belagavi, Karnataka.

Results- A total of 120 cases were included in this study who presented with blunt abdominal trauma. In our study males ( 83 cases) outnumbered females (37 cases) and majority of the cases were in age group of 21-30 years (38.3\%). Most of the cases were from rural background (57.5\%). Road traffic accidents (75.8\%) were the most common reason behind the abdominal trauma. The most common cause of death was shock and haemorrhage (69.2\%). Liver was involved in majority of the victims followed by spleen.

Keywords- Abdominal injuries, Blunt trauma, Road Traffic Accidents

\section{Introduction}

Abdominal trauma is an injury to abdomen and is a common presentation in the emergency room if it is caused by blunt force. The incidences of blunt abdominal trauma are increasing day by day due to the modern industrial era alongwith the development of automobiles. The trauma to abdomen usually occurs

\section{Corresponding Author:}

\section{Dr. Kashif Ali}

Senior Resident, Department of Forensic Medicine, Jawaharlal Nehru Medical College, AMU, Aligarh (UP)- 202002 due to Road Traffic accidents, fall from height, assaults, industrial accidents, etc. Road Traffic Accident (RTA) is one among the top 5 causes of morbidity and mortality in South East Asian countries. ${ }^{1}$ The fatality rate in road traffic accident in India is one of the highest in the world and reported to be 20 times more than that reported in developed countries. ${ }^{2}$ The abdominal cavity contains the vital organs like liver, kidneys, spleen, stomach, small intestine, large intestine, etc and trauma to this region challenges the integrity as well as the viability of an individual. These injuries deserve more detailed thought process as many of these lesions are not immediately fatal and present difficult clinical problems for the surgeon to solve. The solid organs such as liver and spleen are more 
readily lacerated by blows as compared to hollow organs like stomach, intestine, etc. The most important reason for the increase in mortality and morbidity in such cases is either the delay in early diagnosis or misdiagnosis. The extent of blunt abdominal trauma is increasing at an alarming rate as increasing population is relying more on motor vehicles for the transportation. This study was conducted to study the pattern and frequency of intra abdominal injuries seen in autopsy cases with the blunt abdominal trauma.

\section{Materials and Methods}

This retrospective study was conducted over a period of 3 years from January 2016 to December 2018. The total number of cases studied were 120 showing abdominal injuries. This study on medicolegal autopsies was carried out at mortuary of Jawaharlal Nehru Medical
College, Belagavi, Karnataka. The study included data regarding age, gender, cause of accident, type of victim in road traffic accident, cause of death and incidence of visceral injuries of abdomen. All observations were recorded in specially designed proforma for study. Data was collected and then analyzed to determine the results. Statistical analysis was done by using SPSS software version 25 and the results were calculated in percentages.

\section{Results}

A total of 120 cases were included in this study who presented with blunt abdominal trauma. Since there is minimal bony protection for underlying organs, the abdomen is more vulnerable to fatal injuries. In our study males (83 cases) outnumbered females ( 37 cases) and majority of the cases were in age group of 21-30 years (38.3\%) followed by $31-40$ years $(15.8 \%)$ as depicted in Table 1.

Table 1- Distribution of cases according to age and sex

\begin{tabular}{|c|c|c|c|c|}
\hline Age Group & Males & Females & Total no. of cases & Percentage \\
\hline $0-10$ & 1 & 1 & 2 & 1.7 \\
\hline $11-20$ & 7 & 4 & 11 & 9.2 \\
\hline $21-30$ & 34 & 12 & 19 & 38.3 \\
\hline $31-40$ & 11 & 8 & 18 & 15.8 \\
\hline $41-50$ & 12 & 6 & 17 & 14.2 \\
\hline $51-60$ & 13 & 4 & 4 & 3.3 \\
\hline $61-70$ & 3 & 1 & 3 & 2.5 \\
\hline$>70$ & 83 & 37 & 120 & 100 \\
\hline Total & 2 & 1 & & \\
\hline
\end{tabular}

Table 2- Distribution of cases according to Place of Residence

\begin{tabular}{|c|c|c|}
\hline Place of Residence & Number of cases & Percentage \\
\hline Rural & 69 & 57.5 \\
\hline Urban & 51 & 42.5 \\
\hline Total & 120 & 100 \\
\hline
\end{tabular}


As depicted by Table 2, the majority of cases were from rural background (69 cases, $57.5 \%)$ as compared to urban background (51 cases, $42.5 \%$ ).

Table 3- Distribution of cases according to type of accident

\begin{tabular}{|c|c|c|}
\hline Type of Accident & Number of cases & Percentage \\
\hline Road Traffic Accidents & 91 & 75.8 \\
\hline Fall from Height & 18 & 15 \\
\hline Direct Impact of Blunt Object & 6 & 5 \\
\hline Others & 5 & 4.2 \\
\hline Total & 120 & 100 \\
\hline
\end{tabular}

According to Table 3, the most common reason behind the abdominal trauma was road traffic accidents (91 cases, $75.8 \%$ ) followed by fall from height (18 cases, 15\%). 6 cases (5\%) were due to direct impact of blunt object over the abdomen.

Table 4- Distribution of cases according to type of victims in Road Traffic Accidents

\begin{tabular}{|c|c|c|}
\hline Type of Victims in RTA & Number of cases & Percentage \\
\hline Bike Rider & 35 & 38.5 \\
\hline Pillion Rider & 29 & 31.8 \\
\hline Pedestrian & 12 & 13.2 \\
\hline Four wheeler & 11 & 12.1 \\
\hline Cyclist & 4 & 4.4 \\
\hline Total & 91 & 100 \\
\hline
\end{tabular}

As depicted in Table 4, the majority of the victims in Road Traffic Accidents were bike riders (35 cases, 38.5\%) followed by 29 cases of pillion riders (31.8\%) and 12 cases of pedestrian (13.2\%). 11 cases $(12.1 \%)$ were occupant of four wheeler while 4 victims (4.4\%) were cyclist.

Table 5- Distribution of cases according to Cause of Death

\begin{tabular}{|c|c|c|}
\hline Cause of Death & Number of Cases & Percentage \\
\hline Shock and Haemorrhage & 83 & 69.2 \\
\hline Septicaemia & 37 & 30.8 \\
\hline Total & 120 & 100 \\
\hline
\end{tabular}

Shock and haemorrhage was the most common cause of death seen in 83 cases (69.2\%) as compared to 37 cases of septicaemia $(30.8 \%)$ as depicted in Table 5 . 
Table 6- Distribution of cases according to incidence of visceral injuries of abdomen

\begin{tabular}{|c|c|c|}
\hline Visceral Injuries & Number of Cases & Percentage \\
\hline Liver & 21 & 15.5 \\
\hline Spleen & 18 & 12.5 \\
\hline Kidney & 15 & 8.3 \\
\hline Small Intestine & 10 & 4.2 \\
\hline Stomach & 5 & 12.5 \\
\hline Liver, Kidney & 15 & 10.8 \\
\hline Liver, Spleen, Kidney & 13 & 10 \\
\hline Liver, Spleen, Small Intestine & 12 & 9.2 \\
\hline Spleen, Kidney & 11 & 100 \\
\hline Total & 120 & \\
\hline
\end{tabular}

As depicted in Table 6, Liver was involved in majority of the victims (61 cases) followed by spleen (54 cases). Kidney was involved in 54 cases as compared to 22 cases of small intestine. 5 cases of stomach injury were also reported.

\section{Discussion}

In our study, males $(69.2 \%)$ predominated females $(30.8 \%)$ which is similar to the studies conducted by Khajuria et al. ${ }^{3}$ This could be due to the risk taking behavior of males and indulging in outdoor activities as they are the earning members of the family. This study has found that majority of the victims were in the age group 21-30 years (38.3\%) followed by 31-40 years $(15.8 \%)$ because of the fact that persons in this age groups have tendency to take unnecessary risk thereby subjecting themselves to danger of accidents and injuries. This observation is consistent with the studies conducted by Suresh et al. ${ }^{4}$

Most of the cases were from rural background (69 cases, $57.5 \%$ ) as compared to urban background (51 cases, $42.5 \%$ ) which is similar to the study conducted by Reddy et al. ${ }^{5}$ This could be due to the reason of ignorance of road safety rules and traffic sense. In this study, the most common cause of abdominal trauma was road traffic accidents (91 cases, $75.8 \%$ ) followed by fall from height (18 cases, 15\%) which is consistent with the studies conducted by Panchal et al. ${ }^{6}$ Among road traffic accidents, bike riders (38.5\%) constituted maximum number of cases followed by pillion riders $(31.8 \%)$. These results are similar to the studies conducted by Gupta et $\mathrm{al}^{7}$ and Norton et al. ${ }^{8}$

The most common cause of death in our study was shock and haemorrhage $(69.2 \%)$ which is similar to the studies conducted by Ravindra et al. ${ }^{9}$ Liver was involved in majority of the victims (61 cases) followed by spleen (54 cases). Kidney was involved in 54 cases as compared to 22 cases of small intestine. This observation is consistent with the studies conducted by Bakkannavar et $\mathrm{al}^{10}$ and Maurice et al. ${ }^{11}$ Among solid organs, liver was most affected as it is more anteriorly placed and hence more susceptible to injury by blunt trauma.

\section{Conclusion}

In our study abdominal trauma is a major cause of mortality among young adult males of age group 21-30 years. Most of the cases were from rural background. Road Traffic Accidents were the most common cause of injuries followed by fall from height. Liver was involved in majority of the victims followed by spleen. The main cause of death was haemorrhagic shock due to multiple 
injuries. A thorough examination should be done in all road traffic accident cases as many of them show fatal visceral organ damage without external injury. In order to help the authorities to plan better availability of health care on road, the offending agent in Road Traffic Accident should be identified. Awareness of road safety measures, proper attention towards accurate diagnosis and prompt treatment of the accident victim is the need of hour to bring down the mortality as well as the morbidity.

Ethical Clearance- Taken from Institutional Ethical Committee

Conflict of Interest- None

Source of Funding- Self

\section{References}

1) World Health Organization. Regional Office for South-East Asia, New Delhi. Strategic plan for injury prevention and control in South-East Asia. New Delhi. 2002. http://www.searo.who.int Accessed on 2 November 2019.

2) Park K. Accidents and Injuries. Park's Textbook of Preventive and Social Medicine. 21st ed. Jabalpur, India: M/S Banarasidas Bhanot Publishers; 2011. p. 374-9.

3) Khajuria B, Sharma R, Verma A. A Profile of the Autopsies of Road Traffic Accident Victims in Jammu. J Clin Diagnost Res 2008;2:639-42.

4) Suresh Kumar SB, Tanuj K, Ritesh GM, Shankar MB, Vinod CN, Yoganarasimha K. Victim Profile and Pattern of Thoraco-Abdominal Injuries ustained in Fatal Road Traffic Accidents. J Indian Acad Forensic Med 2012;34:17-20.

5) Reddy A, Balaraman R. Epidemiological Study of Two wheeler Accident Victims in Rural South India. J Indian Acad Forensic Med 2016;38(1):325.

6) Panchal HA, Ramanuj AM. The study of abdominal trauma: patterns of injury, clinical presentation, organ involvement and associated injury. Int Surg J 2016;3:1392-8.

7) Gupta V, Kumar A, Gupta P, Singh SP, Singh SP, Singh V et al. Pattern of two wheeler road traffic accidents in rural setting: a retrospective study. Int Surg J. 2016 May;3(2):521-5.

8) Norton R, Matlin SA. The role of health research in the prevention and control of road traffic injuries in South Asia. J Coll Physicians Surg Pak. 2004;14:705-6.

9) Ravindra SH, Vijay Kumar AG, Ajay Kumar TS, Vinay RH. Fatal blunt abdominal trauma - A three year analysis. Indian J Forensic Med Toxicol 2011;5:135-7.

10) Bakkannavar SM, Nayak VC. Victim Profi le and Pattern of Thoraco-Abdominal Injuries Sustained in Fatal Road Traffi c Accidents. J Indian Acad Forensic Med 2012;34:17-20.

11) Maurice EA, Anietimfon UE, Okon OB, Gabriel U, Ogbu N, Cyril A, et al. A Prospective Study of Blunt Abdominal Trauma at the University of Calabar Teaching Hospital, Nigeria. Eur J Trauma Emerg Surg 2012;36:164-8. 